Conclusion: Our results from this real-world RA cohort suggest that monotherapy with bDMARDs is not associated with incident DIP OA but may increase the risk of radiographic progression of existing DIP OA when compared to csDMARDs.

Acknowledgements: We thank all patients and rheumatologists involved for their contribution to the SCQM RA cohort. A list of rheumatology offices and hospitals that contribute to the SCQM registry can be found at http://www.scqm. ch/institutions. The SCQM is financially supported by pharmaceutical industries and donors. A list of financial supporters can be found at http://www.scqm.ch/ sponsors.

Disclosure of Interests: Theresa Burkard: None declared, Christian Lechtenboehmer: None declared, Stephan Reichenbach: None declared, Monika Hebeisen: None declared, Ulrich Walker: None declared, Andrea Michelle Burden: None declared, Thomas Hügle Consultant of: Pfizer, Abbvie, Novartis, Grant/ research support from: GSK, Jansen, Pfizer, Abbvie, Novartis, Roche, MSD, Sanofi, BMS, Eli Lilly, UCB

DOI: 10.1136/annrheumdis-2021-eular.3927

\section{POS0123 NEUROPATHIC PAIN SYMPTOMS IN INFLAMMATORY HAND OSTEOARTHRITIS(OA) LOWERS HEALTH RELATED PHYSICAL QUALITY OF LIFE AND MAY REQUIRE ANOTHER APPROACH THAN ANTI- INFLAMMATORY TREATMENT}

C. Van der Meulen ${ }^{1}$, L. Van de Stadt ${ }^{1}$, F. Kroon ${ }^{1,2}$, M. Kortekaas ${ }^{1}$, A. Boonen ${ }^{3}$ S. Böhringer ${ }^{4}, M_{\text {. Niesters }}^{5}$, M. Reijnierse ${ }^{6}$, F. Rosendaal ${ }^{7}$, N. Riyazi ${ }^{8}$, M. Starmans ${ }^{2}$, F. Turkstra ${ }^{9}$ J. Van Zeben ${ }^{10}$, C. Allaart ${ }^{1}$, M. Kloppenburg ${ }^{1}$. ${ }^{1}$ Leiden University Medical Center (LUMC), Rheumatology, Leiden, Netherlands: ${ }^{2}$ Zuyderland Medical Center, Rheumatology, Heerlen, Netherlands; ${ }^{3}$ Maastricht University Medical Center and Care and Public Health Research Institute, Rheumatology, Maastricht, Netherlands: ${ }^{4}$ Leiden University Medical Center (LUMC), Department of Biomedical Data Sciences, Leiden, Netherlands; ${ }^{5}$ Leiden University Medical Center (LUMC), Anaesthesiology, Leiden, Netherlands; ${ }^{6}$ Leiden University Medical Center (LUMC), Radiology, Leiden, Netherlands; ${ }^{7}$ Leiden University Medical Center (LUMC), Clinical Epidemiology, Leiden, Netherlands; ${ }^{8}$ Haga Hospital, Rheumatology, The Hague, Netherlands; ${ }^{9}$ Amsterdam Rheumatology and Immunology Center Reade, Rheumatology, Amsterdam, Netherlands; ${ }^{10}$ Sint Franciscus Vlietland Groep, Rheumatology, Rotterdam, Netherlands

Background: Pain is a common, difficult to manage symptom in hand osteoarthritis $(\mathrm{OA})$. Multiple pain mechanisms may play a role in hand $\mathrm{OA}$.

Objectives: To investigate presence of neuropathic pain symptoms in patients with inflammatory hand $\mathrm{OA}$, characteristics of those patients, their impact on health related quality of life (HR-QoL), and the influence of anti-inflammatory treatment on neuropathic pain symptoms.

Methods: Data from a randomised, double-blind, placebo-controlled trial of prednisolone including 92 patients with hand OA fulfilling ACR criteria were used. At baseline patients had signs of synovial inflammation, a VAS finger pain of $\geq 30 \mathrm{~mm}$ and who flared $\geq 20 \mathrm{~mm}$ upon NSAID washout. The primary endpoint was VAS finger pain (0-100) at week 6 .

Neuropathic pain symptoms were measured at baseline and week 6 using the validated painDETECT questionnaire, consisting of questions on pain quality, pain intensity over time and radiating pain. Scores range -1 to 38 and patients are classified as having unlikely $(<13)$, indeterminate (13-18) and likely $(>18)$ neuropathic pain. HR-QoL was measured with physical component scale (PCS) of Short-Form 36 (SF36; 0-100), comorbidities with the Self-administered Comorbidities Questionnaire (SCQ; 0-45), radiographic severity with Kellgren-Lawrence $(\mathrm{KL})$ sum score $(0-120)$, and treatment response with OMERACT-OARSI responder criteria.

Association of patient characteristics with neuropathic pain symptoms was analysed with univariate and multivariate ordinal logistic regression, with painDETECT as dependent variable. Association of neuropathic pain symptoms with HR-QoL was analysed with multivariate linear regression, adjusted for age, sex, BMI, VAS finger pain, SCQ score and KL sum score, with PCS as dependent variable. Response of neuropathic pain symptoms and VAS pain to prednisolone was analysed with generalised estimating equations. Association of neuropathic pain symptoms at baseline with response to treatment was analysed using $\chi^{2}$ tests and GEE.

Results: 91 patients had complete painDETECT data at baseline (mean painDETECT score 12.8 [SD 5.9]). Scores were $<13$ in $53 \%, 13-18$ in $31 \%$ and $>18$ in $16 \%$. Higher painDETECT score categories were associated with less radiographic damage, more comorbidities, female sex and higher VAS finger pain in multivariate analysis. (table 1)

Patients with painDETECT scores $>18$ had a lower HR-QoL (PCS $-6.5[95 \% \mathrm{Cl}$ -10.4 to -2.6$]$ ) than those with painDETECT scores $<13$.

PainDETECT scores remained unchanged throughout the trial in both prednisolone-treated and placebo-treated patients, and there was no between-group difference at week 6. VAS pain improved more in the prednisolone group than in the placebo group (mean between-group difference -16.5 [95\% Cl -26.1 to -6.9]) (figure 1). No association between the presence of neuropathic pain symptoms at baseline and OMERACT-OARSI response to treatment was found.

Conclusion: Patients with inflammatory hand $\mathrm{OA}$ and additional neuropathic pain symptoms are more often female and have more comorbidities, and report a lower QoL, than those without. Neuropathic pain symptoms seem unresponsive to anti-inflammatory therapy. Clinicians should be aware of neuropathic pain symptoms in their patients as they might benefit from additional, specific treatment.

Table 1. Ordinal logistic regression with painDETECT categories as dependent variable

\begin{tabular}{lcc}
\hline Variables & Mean (SD) N=91 (100\%) & Odds ratio (95\% Cl) \\
\hline Age & $64(9)$ & $0.96(0.90$ to 1.02$)$ \\
Female sex; N (\%) & $72(79 \%)$ & $3.84(1.19 \text { to } 12.39)^{*}$ \\
BMl; median (SD) & $27(24$ to 29$)$ & $0.97(0.89$ to 1.06$)$ \\
SCQ score; median (SD) & $2(1$ to 5$)$ & $1.04(1.04 \text { to } 1.36)^{*}$ \\
VAS finger pain & $53.8(2.1)$ & $1.02(1.00 \text { to } 1.04)^{*}$ \\
KL sum score & $37(16)$ & $0.96(0.93 \text { to } 1.00)^{*}$
\end{tabular}

${ }^{*} \mathrm{p}<0.05 . \mathrm{BMI}=$ body mass index. $\mathrm{SCQ}=$ Self-administered comorbidities questionnaire VAS $=$ visual analog scale. $\mathrm{KL}=$ Kellgren-Lawrence.

Acknowledgements: The authors thank all patients for their participation in the HOPE study, and participating rheumatologists for inclusion of patients in the HOPE study. We also thank research nurses B.A.M.J. van Schie-Geyer and S Wongsodihardjo, and technicians J.C. Kwekkeboom and E.I.H. van der Voort, for their contributions.

Figure 1

Development of pain scores over time
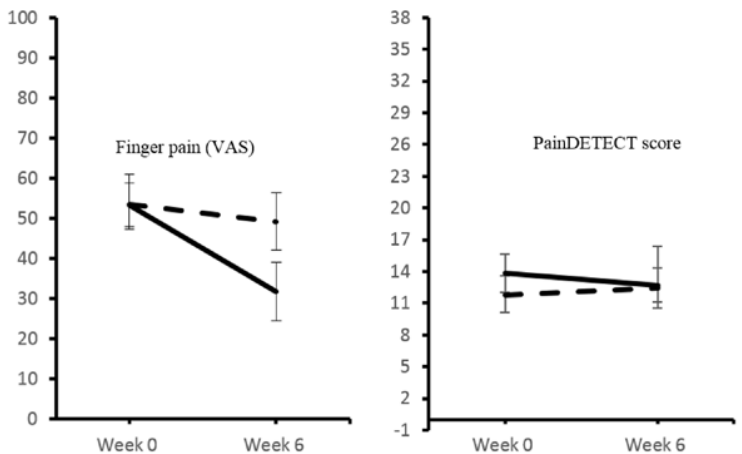

Figure 1. Mean score at week 0 and week 6, per treatment arm, for VAS finger pain and PainDETECT. Placebo shown in dashed line, prednisolone $10 \mathrm{mg}$ daily in solid line. Whiskers indicate $95 \% \mathrm{CI}$

Disclosure of Interests: Coen van der Meulen: None declared, Lotte van de Stadt: None declared, Féline Kroon: None declared, Marion Kortekaas: None declared, Annelies Boonen Speakers bureau: Lecture for UCB; paid to department., Consultant of: Yes. Advisory board meetings at Galapagos, Eli Lilly and Abvvie; paid to department., Grant/research support from: Yes. Grants by Celgene and Abbvie; paid to department., Stefan Böhringer: None declared, Marieke Niesters: None declared, Monique Reijnierse: None declared, Frits Rosendaal: None declared, Naghmeh Riyazi: None declared, M. Starmans: None declared, Franktien Turkstra: None declared, Jende van Zeben: None declared, Cornelia Allaart: None declared, Margreet Kloppenburg Consultant of: For Abbvie, Pfizer, Levicept, GlaxoSmithKline, Merck-Serono, Kiniksa Flexìn, Galapagos, Jansen, CHDR and local investigator of industry-driven trial (Abbvie). All fees were paid to the institution., Grant/research support from: Grant by the Dutch Arthritis Society DOI: 10.1136/annrheumdis-2021-eular.692

\section{POS0124 \\ QUALITY OF LIFE FOR PATIENTS WITH KNEE OSTEOARTHRITIS WITH OR WITHOUT PAIN SENSITIZATION}

W. R. Goh'1, W. J. Ong ${ }^{2}$, D. Chan ${ }^{3}$, Y.Y. Leung ${ }^{1} .{ }^{1}$ Singapore General Hospital, Rheumatology \& Immunology, Singapore, Singapore; ${ }^{2}$ Duke-NUS Medical School, Singapore, Singapore; ${ }^{3}$ Singapore General Hospital, Pain Medicine, Singapore, Singapore

Background: Patients with central sensitization (CS) may have poorer quality of life (QOL). 
Objectives: We aim to evaluate whether different ways of classifying CS have an impact on a patient's QOL among patients with knee osteoarthritis (KOA). Methods: We use the baseline pre-operative data from a cohort of consecutive KOA patients enlisted for knee replacement surgery (1). We collected demographics, number and position of painful sites of body. Quality of life was assessed by the Medical Outcome Survey Short-Form 36 (SF-36). Pain pressure threshold was measured at volar side of right forearm. We classify CS using three sets of criteria: 1). widespread pain (pain involving both upper/ lower trunk, and both side of body), 2). lowest $10^{\text {th }}$ percentile of pressure pain threshold (PPT) measured at the forearm and 3 ) the painDETECT questionnaire $>=13 / 38$.

Results: Of 233 patients (79.8\% women) with complete data set for analysis, mean (standard deviation, SD) age was 66.0 (8.3) years. 15.5\%, 25.8\%, and $4.7 \%$ of patients were classified as having CS by widespread pain, low PPT and painDETECT criteria. KOA patients with CS have poorer QoL compared with those without. Low PPT identified patients with poorer general health, while widespread pain and PainDETECT criteria identified patients with poorer QoL in more domains including vitality mental health (Table 1 ).

Conclusion: KOA patients who have CS have poorer QoL compared to those without. Different criteria defined patients with different pattern of QoL impacts. In general, KOA patients who have CS have poorer QoL compared to those without. This highlight the importance of additional impact of CS to QoL

Table 1. Quality of life comparing patients with or without CS

\begin{tabular}{|c|c|c|c|c|c|c|}
\hline & \multicolumn{2}{|c|}{ Widespread pain } & \multicolumn{4}{|c|}{$\begin{array}{l}\text { lowest } 10^{\text {th }} \text { percentile PainDETECT }>=13 / 38 \\
\text { of forearm PPT }\end{array}$} \\
\hline & $\begin{array}{c}\text { No } \\
(n=197)\end{array}$ & $\begin{array}{c}\text { Yes } \\
(n=36)\end{array}$ & $\begin{array}{c}\text { No } \\
(n=206)\end{array}$ & $\begin{array}{c}\text { Yes } \\
(n=27)\end{array}$ & $\begin{array}{c}\text { No } \\
(n=222)\end{array}$ & $\begin{array}{c}\text { Yes } \\
(n=11)\end{array}$ \\
\hline SF-Physical functioning & 39.0 & $32.6(19.0)$ & $38.7(21.8)$ & $32.8(17.8)$ & ) $38.8(21.3)$ & $22.3(19.2)^{*}$ \\
\hline SF-Role physical & 21.6 & $8.3(22.4)^{\star}$ & $20.3(32.2)$ & 13.9 & ) $19.7(32.6)$ & $15.9(23.1)$ \\
\hline SF-Bodily pain & $36.3(19.5)$ & $28.1(14.0)^{\star}$ & * $35.1(19.5)$ & 34.0 & $35.5(19.1)$ & $24.2(13.3)$ \\
\hline SF-General health & 68.9 & $64.6(20.3)$ & ) $69.4(20.6)$ & $59.3(22.4)^{3}$ & *68.7(20.7) & $58.4(25.7)$ \\
\hline SF-Vitality score & 69.7 (22.4) & $59.3(20.4)^{\star \star}$ & * 68.8 & $63.1(21.1)$ & $69.0(21.8)$ & $51.8(29.2)^{*}$ \\
\hline SF-Social functioning & $57.7(37.2)$ & $48.3(39.2)$ & $57.3(38.0)$ & $48.1(33.7$ & 56.7 (37.7) & $47.7(42.1)$ \\
\hline SF-Role emotion & $86.1(34.4)$ & 86.1 (33.2) & $86.7(33.5)$ & $79.0(38.3$ & 86.9 & $63.6(50.5)$ \\
\hline SF-Mental health & $82.4(16.2)$ & $77.4(19.2)$ & $82.2(16.8)$ & $77.8(15.8)$ & $82.2(16.3)$ & $70.2(22.2)^{\star}$ \\
\hline $\begin{array}{l}\text { Physical component } \\
\text { score }\end{array}$ & $32.5(10.1)$ & $30.3(8.0)$ & $32.4(9.8)$ & $30.6(9.7)$ & $32.4(9.9)$ & 28.8 \\
\hline $\begin{array}{l}\text { Mental component } \\
\text { score }\end{array}$ & $53.0(10.5)$ & $48.3(10.0)^{*}$ & * $52.7(10.6)$ & $48.5(9.2)$ & $52.6(10.2)$ & $44.2(13.7)^{\star \star}$ \\
\hline
\end{tabular}

${ }^{*} p<0.05 ;{ }^{* *} p<0.01$

\section{REFERENCES:}

[1] Leung YY, Lim Z, Fan Q, et al. Pre-operative pressure pain thresholds do not meaningfully explain satisfaction or improvement in pain after knee replacement: a cohort study. Osteoarthritis and cartilage 2019;27(1):49-58.

Disclosure of Interests: None declared

DOI: 10.1136/annrheumdis-2021-eular.1698

\section{POS0125 CALCULATING RISK OF HAND OSTEOARTHRITIS PROGRESSION AT TEN YEARS THROUGH A PREDICTION MODEL}

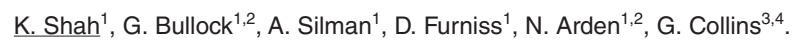
${ }^{1}$ University of Oxford, Nuffield Department of Orthopaedics, Rheumatology, and Musculoskeletal Sciences, Oxford, United Kingdom; ${ }^{2}$ University of Oxford, Centre for Sport, Exercise and Osteoarthritis Research, Versus Arthritis, Oxford, United Kingdom; ${ }^{3}$ University of Oxford, Centre for Statistics in Medicine, Nuffield Department of Orthopaedics, Rheumatology, and Musculoskeletal Sciences, Oxford, United Kingdom; ${ }^{4}$ Oxford University Hospitals NHS Foundation Trust, NIHR Oxford Biomedical Research Centre, Oxford, United Kingdom

Background: Hand osteoarthritis $(\mathrm{OA})$ is a chronic, progressive disease, commonly affecting middle aged women. OA at the interphalangeal joints (IPJs) or the thumb base are considered different disease subsets (1). Few studies have investigated individual risk factors for IPJ OA progression (2). Prediction models can be used to calculate overall disease risk from multiple risk factors. This can guide prevention and treatment options.

Objectives: Develop and internally validate a prediction model for IPJ OA progression.

Methods: Data from the Chingford 1000 Women Study (Chingford Study), the largest population-based cohort worldwide assessing hand OA, was used. It is representative of the middle-aged female population in the United Kingdom (3). At baseline, 1,003 women aged 45 to 64 years' old were recruited, and 693 measurements taken. Hand radiographs were taken at baseline and after ten years, read using the Kellgren-Lawrence (KL) atlas (inter-observer correlation: $\geq 0.7(4)$ ).
For the current study, participants must have had $\mathrm{OA}$ ( $K L \geq 2$ in $\geq 1 \mathrm{IPJ}$ ) on baseline hand radiographs. Participants with KL 4 in all 16 IPJs at baseline were excluded. Risk factors from the Chingford Study at baseline were selected by biological plausibility, literature evidence (2), and hand surgeons' consensus (5): age (years), occupation (manual versus non manual), $O A$ in $\geq 1$ thumb base (KL $\geq 2$ versus $K L<2$ ), body mass index (BMI) $\left(\mathrm{kg} / \mathrm{m}^{2}\right.$ ), family history of hand $\mathrm{OA}$ (yes versus no). The outcome was defined on an ordinal scale for the number of IPJs (up to $>5$ IPJs) with OA progression (increase by $K L \geq 1$ ), at ten years'

The prediction model was developed using a penalized proportional odds logistic regression. Odds ratios (95\% confidence intervals) were reported for each risk factor. The model was internally validated using 2,000 bootstrap iterations. Model performance was assessed for discrimination (C-statistic), and calibration (C-slope). $3.5 \%$ of data was missing, and complete case analysis was used. Results: 699 women had baseline hand radiographs: 38 were unreadable, 459 had no IPJ OA. Seven participants had missing data (occupation: 5, BMl: 1, family history: 1) and were excluded. 195 participants were included this study. Median age at baseline was 59 (interquartile range: 8 ) years.

$181(92.8 \%)$ participants had OA progression at 10 years (Figure 1). Thumb base OA (odds ratio: 1.32 (0.93 to 1.88)) was most strongly associated with IPJ OA progression (Table 1). C-statistic was 0.57 , and calibration slope was 1.38 for the optimism-corrected model.

Conclusion: More stringent cut-offs for OA progression would be clinically useful. It was only weakly possible to predict which participants with IPJ OA would progress. This suggests that other risk factors, such as gender, ethnicity and genetics, may be predominant.

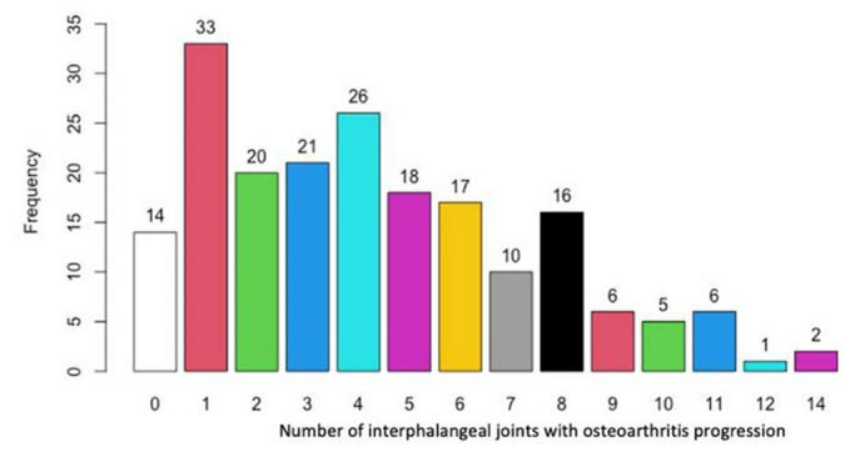

Figure 1. Hand interphalangeal joints with osteoarthritis progression (Kellgren-Lawrence grade $\geq 1$ ) at 10 years' follow up

Table 1. Odds ratios for risk factors

\begin{tabular}{lc}
\hline Risk factor & $\begin{array}{c}\text { Odds ratio } \\
\text { (95\% confidence interval) }\end{array}$ \\
\hline $\begin{array}{l}\text { Age (years) } \\
\text { Occupation } \\
\text { (manual versus non manual) }\end{array}$ & $1.02(0.99$ to 1.06$)$ \\
$\begin{array}{l}\text { Thumb base } \mathrm{OA} \\
\text { (Kellgren-Lawrence grade } \geq 2 \text { versus }<2)\end{array}$ & $1.88(0.60$ to 1.29$)$ \\
$\begin{array}{l}\text { Family history of hand OA } \\
\text { (yes versus no) }\end{array}$ & 1.92 to 1.88$)$ \\
Body mass index $\left(\mathrm{kg} / \mathrm{m}^{2}\right)$ & $1.03(0.72$ to 1.45$)$ \\
\hline
\end{tabular}

OA: Osteoarthritis

\section{REFERENCES:}

[1] Kloppenburg M, et al. Research in hand osteoarthritis: time for reappraisal and demand for new strategies. Ann Rheum Dis. 2007;66(9):1157-61.

[2] Shah K, et al. Risk factors for the progression of finger interphalangeal joint osteoarthritis: a systematic review. Rheumatol Int. 2020;40(11):1781-1792.

[3] Hart DJ, Spector TD. The relationship of obesity, fat distribution and osteoarthritis in women in the general population: the Chingford Study. J Rheumatol. 1993;20:331-335.

[4] Hart DJ, et al. Reliability and reproducibility of grading radiographs for osteoarthritis of the hand. Br J Rheum. 1993;32:S1.

[5] Shah K, et al. Delphi consensus of risk factors for development and progression of finger interphalangeal joint osteoarthritis. J Hand Surg Eur Vol. 2019;44(10):1089-1090.

Acknowledgements: We would like to thank all of the participants of The Chingford 1000 Women Study, Professor Tim Spector, Dr Deborah Hart, Dr Alan Hakim, Maxine Daniels, Alison Turner, James van Santen and Julie Damnjanovic for their time and dedication. 